\title{
Effects of High-Speed Rail on Regional Economic Growth and Employment in China
}

\author{
Li WANG ${ }^{1}$, Lu SHEN ${ }^{1}$ and Fei XUE ${ }^{2 *}$ \\ 1 Northwest University, Xi'an, China; wlily218@126.com;936627973@qq.com \\ 2 University of Chinese Academy of Social Sciences, Beijing, China; 201620145@stumail.nwu.edu.cn \\ * Corresponding author: 201620145@stumail.nwu.edu.cn
}

\begin{abstract}
High-Speed Rail (HSR) has an important impact on the economic growth and employment of cities along the line. Based on the data of 284 prefecture-level cities in China from 2007 to 2015, this paper analyzes the impact of HSR construction on the economy and employment in cities along the line at the national and sub-regional levels using the difference-in-differences model. The research results show that China's high-speed rail construction has failed to promote economic growth in the sample cities taken as a whole, but significantly improved the short-term employment levels in cities along the line. Moreover, there is obvious heterogeneity in the impact of HSR. The economic inhibitory effect of HSR is mainly reflected in the eastern region, while the employment promotion effect is mainly reflected in the central region. Finally, the effect of HSR on economic growth is a result of the change in the investment and degree of openness.
\end{abstract}

Keywords: high-speed railway; difference-in-differences; economic effect; employment effect; heterogeneous effects

JEL Classification: O18; R11

\section{Introduction}

China's High-Speed Rail (HSR) construction is a landmark event in the recent history of transportation infrastructure not only in China, but the world over. The "space-time compression" effect brought about by HSR is becoming an important factor in transforming the layout of the national economy and rebuilding the spatial pattern of cities along the line (Chen, 2012; Deng et al., 2017; Dong \& Zhu, 2016). The rapid spread of China's HSR passenger transport network has improved accessibility between regions and cities and reduced travel costs. This has, in turn, induced a rapid flow and frequent interchange of population as well as logistics, information, and capital among regions. It has a comprehensive and profound impact on the employment and economic development in the areas along the line and also those within the cities.

Compared with the HSR networks abroad, which have been in operation for more than half a century, the construction of China's HSR started relatively late. In 2003, the Qinhuangdao-Shenyang Passenger Dedicated Line, the first HSR in China, was completed and opened to traffic. Implementation of the "Medium and Long-Term Railway Network Plan", promulgated in 2004, inaugurated a new era of HSR construction. The Beijing-Tianjin Inter-city HSR, which opened to traffic in 2008, marked China's official entry into the "High- 
speed Rail era." Since then, a new batch of HSR lines has been operationalized every year. In order to meet the rapidly growing passenger demand and optimize the development space for regional development, the "Medium and Long-Term Railway Network Plan," promulgated by the State Council in July 2016, proposed the construction of "eight vertical and eight horizontal" HSR and planned to build a 38,000 km HSR network by 2025. At the end of 2016, HSR operation mileage in China exceeded 22,000 km, accounting for $60 \%$ of the total HSR operation mileage in the world. The White Paper "Development of Transport in China" issued by the Information Office of the State Council proposes that the HSR network will cover more than $80 \%$ of the major cities by 2020 . Under the dual constraints of the demographic dividend decline and the depletion of resources and the environment, HSR is regarded as the driver of development along the line, leading to a "scramble" for HSR tracks and stations. At present, large-scale HSR construction provides the Chinese government with a chance to achieve major changes in the economic sphere. What kind of role does HSR play in regional economic growth and employment? What is the mechanism behind this impact? We focus on these issues not only to assess the effectiveness the large-scale HSR investment but also to provide a quantitative interface for the implementation of an optimum transport infrastructure policy with the strategic objective of narrowing regional disparities and achieving coordinated regional development.

Studies on HSR cover the promotion of regional economic integration (Zhang \& Nie, 2010) and population migration ( $\mathrm{Li}$ et al., 2014) to achieve accessibility (Donaldson \& Hornbeck, 2016; Liu, 2013), leading to urban development and urban spatial evolution (Duranton \& Turner, 2012; Wang \& Nian, 2014). With the opening of more HSR lines, people are beginning to consider whether the HSR established in their area will bring them the expected payoff. Sasaki et al. (1997) analyzed the urban regional economic system along the Shinkansen in Japan and found that the ability of the regional central cities to achieve economic agglomeration was strengthened as the degree of networking of the Shinkansen. Tan and Zhong (2014) found, by analyzing data from 177 cities along the line in China, that HSR benefited economic agglomerations by improving the accessibility of cities along the line. Li et al. (2016a) studied 226 cities at the prefecture level or above and found a significant spatial gradient gap in the impact of HSR on economic agglomerations.

According to the research report of the National Railway Bureau in 2017, HSR cities have $72 \%$ more GDP and 55\% more sustainable development than those with no railway. However, there is disagreement on whether HSR plays a significant role in promoting the economic growth of cities and the regions around them. Researchers hold that HSR plays an important role in the economic growth of a region through the spillover effect of the space economy (Zhang, 2012; Wang \& Ni, 2016). HSR also drives regional economic growth by influencing the supply of effective labor or wage levels (Dong \& Zhu, 2016). However, the high travel costs associated with HSR tend to cause an economic slowdown. As a result, the construction of HSR has no significant effect on the economic growth in the areas along the line in the short term (Li et al., 2016b; Wang \& Nian, 2014). Although HSR will enhance the advantages of regional central cities, it will also have a "tunnel effect" on small and mediumsized cities along the line, and thus, will thus inhibit the economic and employment 
development of small cities (Hall, 2009; Ortega et al, 2012; Yu, 2017). Some scholars have also proposed that the launch of HSR would have the "siphon effect" of reducing the economic growth of non-regional central cities along the line (Zhang \& Tao, 2016).

Based on the relevant literature both at home and abroad, this paper focus on the following aspects. First, we assess the impact of HSR on economic growth and employment from the perspective of cities of the prefecture level and above, this makes the results more reliable. Second, considering the large-scale HSR construction in China as a quasi-natural experiment, we use the DID method, which is commonly used in policy evaluation, to estimate HSR effects, this helps us to recognize more clearly the causal effect between HSR and the growth of the economy and employment. We also conduct a series of robustness tests to ensure the accuracy of the regression results. Third, selecting the period before 2007 as the sample may lead to estimation bias caused by the six speed increments in train speed between 1997 to 2007, and thus we select the sample period from 2007 to 2015.

This paper is structured as follows: Section 2 presents the data and describes the econometric methodology. Section 3 provides the results of the empirical analysis, while Section 4 conducts a series of robustness tests. Section 5 analyzes the mechanism through which the HSR economic impact occurs. Section 6 presents our conclusions and policy recommendations.

\section{Data and Methodology}

To assess the economic and employment effects of HSR, we collect data on the HSR opening time, the economic growth and employment level of each city, and other city-level characteristics. This section mainly presents the data and describes the econometric methodology.

\subsection{Data}

Because HSR stations are often built in the suburbs, we select city data for research. Taking into account the adjustment for administrative districts and missing data, we leave out cities such as Lhasa, Haidong, Chaohu, Sansha, Tongrn, Bijie and Puer. In addition, to avoid the estimation bias caused by the six increments in train speed between 1997 and 2007, we selected panel data on 284 Chinese cities at the prefecture level or above for the 2007-2015 period. The main data are obtained from the China Entrepreneur Investment Club (CEIC) and China Stock Market \& Accounting Research (CSMAR) databases; the City Statistical Yearbook series is also used to obtain data. To eliminate potential heteroskedasticity, we logtransformed all variables.

We use real GDP per capita and employment density as the measures of the regional economy and employment level, respectively. The GDP deflator for each city with 2007 as the base year is calculated with the GDP price index provided in the CEIC database. The employment density of city $s$ in year $t$ is defined as $\mathrm{ED}_{\mathrm{st}}=$ Employment $_{\mathrm{st}} /$ Areast.

To set the HSR dummy variable (HSR_city) for each city, we collect data on the year of commencement of HSR operations according to the Medium and Long-term Railway Plan and the actual state of HSR operations in all prefecture level cities. The HSR dummy variable 
for the current year equals one if the date of commencement of HSR operations is in the first half of the year (by June 30). However, if the date falls in the second half of the year, the HSR dummy variable for the next year is set as one.

Five control variables of interest are included in our research. First, regional fixed investment is a primary driver of economic growth. We measure fixed investment (Invest) using the ratio of regional fixed investment to GDP. Second, the government plays an indispensable role in China's economic growth. We measure government's role in economic development (Gov) using the ratio of local government expenditure to GDP. Third, trade openness (Open) directly affects regional economic growth. We use the ratio of total regional imports and exports to GDP as a proxy. Finally, other infrastructure measures are included, which are defined as the logarithm of the number of public transportation vehicles per 10,000 population (Log_Bus) and the logarithm of the per capita area of paved roads in city (Log_Road).

\subsection{Econometric Methodology}

Generally, the economic growth and employment levels of a city are affected by not only the HSR policy, but also by the date on which HSR operations commenced in the city. The change in the economic environment over time will play an important role. The main purpose of our paper is to examine the policy effect of HSR operations. Thus, the key issue is the manner of eliminating the time and other policy effects from the total effect. The DID method, as one of the most common estimation methods of treatment effects, can help us to observe the changes resulting from policy implementation, assuming that the time trends of the treated and untreated groups are common. Therefore, we choose this methodology as a measure of the economic and employment effects of HSR.

However, the traditional DID model requires that the execution time of the policy should be the same, but the date of commencement of HSR operations varies in our sample, this prevents us from setting a policy time dummy variable. Following Beck et al. (2010) and Hoynes et al. (2016), we focus on the sign and significance of interaction terms between the treated group dummy and the policy time dummy. Furthermore, controlling for the city-level fixed effect and year fixed effect, we can take care of any city-specific yearly shocks on the local economic and employment conditions. The benchmark model is of the following form:

$$
Y_{s t}=\alpha+\beta H S R_{-} \text {city }_{s t}+\delta X_{s t}+v_{t}+\mu_{s}+\varepsilon_{s t}
$$

In this equation, $Y_{s t}$, as an explained variable, represents the economic or employment situation in city $s$ in year $t . \mu_{s}$ and $v_{t}$ are the vectors for city dummy variable and year dummy variable, respectively, which measure city and year fixed-effects. The control variable $X_{s t}$ measures the degree of trade openness, investment, government spending, and other citylevel characteristics. $\varepsilon_{s t}$ is the error term. The variable of interest is the interaction term HSR_cityst, which is equal to one for the years after the year in which HSR operation commences in city s and zero otherwise. The coefficient $\beta$ indicates the impact of HSR on economic growth and employment. A positive and significant $\beta$ suggests that HSR exerts a 
positive effect on the economy or employment in cities along the line, while a negative and significant $\beta$ indicates that it is not conducive to economic growth and employment.

The DID model can help us effectively identify the effect of HSR. However, the primary challenge in using this identification strategy is the endogenous selection of infrastructure. In other words, the non-random construction of infrastructure, such as HSR, adds to the difficulty of estimating the causal effect (Datta, 2012). This means that there are systematic differences between the cities that open HSR and those that do not. However, Chandra and Thompson (2000) proposed that many large-scale transportation infrastructure projects can be viewed as an exogenous shock to the area through which they pass because their purpose is to connect two places. Furthermore, according to Medium and Long-term Railway Plan (adjusted in 2008), one of the purposes of HSR construction is to connect capital cities, as well as large and medium-sized cities. Therefore, following Chandra and Thompson (2000) and Datta (2012), we leave out the node cities (including capital cities, vice provincial cities, and municipalities) to eliminate the endogeneity problem. The final sample includes 253 cities.

\section{Estimation Results}

\section{1 .Preliminary Results}

Table 1 shows the results of the benchmark regression, which assesses the impact of the opening of HSR on economic growth and employment. In columns 1 and 6, the regressions simply control for city and year fixed effects. In the other columns, we also control for gross fixed investment as percentage of GDP, fiscal expenditure as percentage of GDP, total import and export as percentage of GDP, the logarithm of the number of public transportation vehicles per 10,000 population, and the logarithm of the per capita area of paved roads in city.

Table 1 show that the HSR dummy variable enters negatively and significantly at the $10 \%$ level in columns 1 and 2, but positively and significantly at the $5 \%$ level in columns 6 and 7 , indicating that the commencement of HSR operation substantially inhibits economic growth but improves the level of employment. Specifically, the results in column 2 suggest that HSR induced a 1.5\% reduction in per capita GDP, whereas those in column 7 show a $4.8 \%$ growth in employment owing to HSR. The reason behind this phenomenon may be the "space-time compression" effect brought about by HSR. It accelerates the flow of economic resources from the periphery to the middle cities, improving the competitiveness and market access of this region. Further, there would be a negative impact on the economic growth of small and medium-sized cities along the HSR; this is called the "siphon effect." Further, labor demand, the anticipated effect on the labor force, and the polarization effect brought about by the HSR would induce the transfer of the non-HSR labor force to cities with advantageous locations. 
Table 1. The impact of HSR on regional economic growth and employment: basic results

\begin{tabular}{|c|c|c|c|c|c|}
\hline Variables & All cities & All cities & Eastern Cities & Middle Cities & Western Cities \\
\hline & \multicolumn{5}{|c|}{ Economic Effects: Log_GDPP } \\
\hline & $(1)$ & $(2)$ & (3) & $(4)$ & $(5)$ \\
\hline \multirow[t]{2}{*}{ HSR_city } & $-0.018^{*}$ & $-0.015^{*}$ & $-0.024^{* *}$ & $0.029^{* *}$ & 0.008 \\
\hline & -0.009 & -0.009 & -0.011 & -0.014 & -0.019 \\
\hline Observations & 2250 & 2242 & 768 & 828 & 646 \\
\hline \multirow[t]{3}{*}{$\mathrm{R} 2$} & 0.96 & 0.961 & 0.976 & 0.952 & 0.973 \\
\hline & \multicolumn{5}{|c|}{ Employment Effect: Log_ED } \\
\hline & $(6)$ & $(7)$ & $(8)$ & $(9)$ & $(10)$ \\
\hline \multirow[t]{2}{*}{ HSR_city } & $0.063^{* *}$ & $0.048^{* *}$ & 0.021 & $0.061^{* *}$ & -0.03 \\
\hline & -0.026 & -0.022 & -0.04 & -0.027 & -0.032 \\
\hline Observations & 2250 & 2242 & 768 & 828 & 646 \\
\hline $\mathrm{R} 2$ & 0.426 & 0.443 & 0.489 & 0.426 & 0.548 \\
\hline Controls & $\mathrm{NO}$ & YES & YES & YES & YES \\
\hline Year fixed effect & YES & YES & YES & YES & YES \\
\hline City fixed effect & YES & YES & YES & YES & YES \\
\hline
\end{tabular}

Notes: Standard errors, which appear within parentheses, are heteroskedasticity robust and clustered at the city level. ${ }^{*}{ }^{* *}$, and ${ }^{* *}$ indicate statistical significance at the $10 \%, 5 \%$, and $1 \%$ levels, respectively.

Table 1 also shows the impact of HSR on different regions. The negative and significant coefficients for the eastern cities in columns 3 and 7 indicate that HSR not only failed to promote economic growth and employment, but also had an inhibitory effect on their economy. Columns 4 and 8 show that HSR significantly promoted economic growth and employment in the middle cities. Furthermore, columns 5 and 10 show that the economic and employment effects in the western cities are not significant. HSR has had heterogeneous economic and employment effects in the regions. This may be mainly related to the spatial economic agglomeration ability of middle cities in different regions. The central agglomerations in the eastern coastal areas are much more concentrated than those in other regions. Therefore, HSR created a "siphon effect" in the eastern region and failed to promote economic growth and employment there. Benefiting from HSR, cities in the middle region consistently leveraged their transport advantages to attract labor and promote economic growth. Moreover, because of the late start of HSR in the western region, most of the cities there had no HSR during the sample period, and therefore, did not experience the HSR effect.

\subsection{Measuring Annual Treatment Effects}

In addition to the average effect, we also estimate the dynamic impact of HSR on economic growth and employment. Generally, the impact of the HSR on economic growth and employment would continue to accumulate with the speeding up of HSR construction and improvement of the network. We examine this assumption by introducing interaction terms between the year dummy variables and the HSR dummy variables:

$$
\log \left(Y_{s t}\right)=\alpha+\sum_{j=1}^{8} \beta_{j} D_{s t}^{j}+\delta X_{s t}+v_{t}+\mu_{s}+\varepsilon_{s t}
$$


where $D j$ represents the year dummy variable in the $j$ th year after HSR's opening. For example, $D j$ is equal one for cities in the $j$ th year after the opening of HSR, otherwise, zero. $\beta j$ measures the impact on economic growth and employment after the $j$ th year. In addition, the model includes a series of control variables, and we use a two-way fixed effect model to regress at the national and sub-regional levels. The results are shown in Table 2.

Table 2. The impact of HSR on regional economic growth and employment levels: dynamic effect

\begin{tabular}{|c|c|c|c|c|c|c|c|c|}
\hline \multirow[b]{2}{*}{ Variables } & \multicolumn{4}{|c|}{ Economic Effects: Log_GDPP } & \multicolumn{4}{|c|}{ Employment Effect: Log_ED } \\
\hline & $\begin{array}{l}\text { All Cites } \\
\text { (1) }\end{array}$ & $\begin{array}{c}\text { Eastern } \\
\text { Cities } \\
(2)\end{array}$ & $\begin{array}{c}\text { Middle } \\
\text { Cities } \\
\text { (3) }\end{array}$ & $\begin{array}{c}\text { Western } \\
\text { Cities } \\
(4)\end{array}$ & $\begin{array}{l}\text { All Cites } \\
\text { (5) }\end{array}$ & $\begin{array}{c}\text { Eastern } \\
\text { Cities } \\
(6)\end{array}$ & $\begin{array}{c}\text { Middle } \\
\text { Cities } \\
(7)\end{array}$ & $\begin{array}{c}\text { Western } \\
\text { Cities } \\
(8)\end{array}$ \\
\hline $\mathrm{D}^{1}$ & $\begin{array}{l}-0.011 \\
(0.007)\end{array}$ & $\begin{array}{l}-0.011 \\
(0.008)\end{array}$ & $\begin{array}{c}0.013 \\
(0.011)\end{array}$ & $\begin{array}{l}-0.001 \\
(0.016)\end{array}$ & $\begin{array}{l}0.039 * * \\
(0.018)\end{array}$ & $\begin{array}{c}0.034 \\
(0.034)\end{array}$ & $\begin{array}{l}0.060^{* *} \\
(0.026)\end{array}$ & $\begin{array}{l}-0.024 \\
(0.029)\end{array}$ \\
\hline $\mathrm{D}^{2}$ & $\begin{array}{l}-0.007 \\
(0.009)\end{array}$ & $\begin{array}{l}-0.014 \\
(0.010)\end{array}$ & $\begin{array}{l}0.039^{* *} \\
(0.015)\end{array}$ & $\begin{array}{c}0.010 \\
(0.026)\end{array}$ & $\begin{array}{c}0.064^{* * *} \\
(0.023)\end{array}$ & $\begin{array}{c}0.041 \\
(0.038)\end{array}$ & $\begin{array}{l}0.071^{* *} \\
(0.030)\end{array}$ & $\begin{array}{l}-0.011 \\
(0.037)\end{array}$ \\
\hline $\mathrm{D}^{3}$ & $\begin{array}{l}-0.018 \\
(0.012)\end{array}$ & $\begin{array}{c}-0.031^{* *} \\
(0.014)\end{array}$ & $\begin{array}{l}0.051^{* *} \\
(0.021)\end{array}$ & $\begin{array}{l}0.045^{* *} \\
(0.019)\end{array}$ & $\begin{array}{l}0.063^{* *} \\
(0.030)\end{array}$ & $\begin{array}{c}0.016 \\
(0.051)\end{array}$ & $\begin{array}{l}0.074^{* *} \\
(0.035)\end{array}$ & $\begin{array}{l}-0.091^{*} \\
(0.046)\end{array}$ \\
\hline $\mathrm{D}^{4}$ & $\begin{array}{c}-0.031^{* *} \\
(0.014)\end{array}$ & $\begin{array}{c}-0.037^{* *} \\
(0.017)\end{array}$ & $\begin{array}{l}0.035^{*} \\
(0.021)\end{array}$ & $\begin{array}{l}0.046^{* *} \\
(0.019)\end{array}$ & $\begin{array}{c}0.044 \\
(0.034)\end{array}$ & $\begin{array}{c}0.004 \\
(0.055)\end{array}$ & $\begin{array}{c}0.029 \\
(0.033)\end{array}$ & $\begin{array}{c}-0.136^{* *} \\
(0.058)\end{array}$ \\
\hline $\mathrm{D}^{5}$ & $\begin{array}{l}-0.029^{*} \\
(0.016)\end{array}$ & $\begin{array}{l}-0.035^{*} \\
(0.020)\end{array}$ & $\begin{array}{l}0.048^{*} \\
(0.026)\end{array}$ & $\begin{array}{c}0.059^{* * *} \\
(0.019)\end{array}$ & $\begin{array}{c}0.022 \\
(0.034)\end{array}$ & $\begin{array}{l}-0.018 \\
(0.058)\end{array}$ & $\begin{array}{c}0.005 \\
(0.039)\end{array}$ & $\begin{array}{c}-0.104^{* *} \\
(0.046)\end{array}$ \\
\hline $\mathrm{D}^{6}$ & $\begin{array}{l}-0.027 \\
(0.020)\end{array}$ & $\begin{array}{l}-0.023 \\
(0.024)\end{array}$ & $\begin{array}{c}0.040 \\
(0.036)\end{array}$ & $\begin{array}{l}0.090^{* *} \\
(0.035)\end{array}$ & $\begin{array}{l}-0.005 \\
(0.039)\end{array}$ & $\begin{array}{l}-0.044 \\
(0.065)\end{array}$ & $\begin{array}{c}0.000 \\
(0.063)\end{array}$ & $\begin{array}{c}-0.148^{* * *} \\
(0.052)\end{array}$ \\
\hline $\mathrm{D}^{7}$ & $\begin{array}{l}-0.031 \\
(0.033)\end{array}$ & $\begin{array}{l}-0.034^{*} \\
(0.019)\end{array}$ & $\begin{array}{c}0.072 \\
(0.073)\end{array}$ & & $\begin{array}{l}-0.046 \\
(0.051)\end{array}$ & $\begin{array}{c}-0.143^{* *} \\
(0.069)\end{array}$ & $\begin{array}{l}-0.000 \\
(0.095)\end{array}$ & \\
\hline $\mathrm{D}^{8}$ & $\begin{array}{c}-0.064^{* *} \\
(0.025)\end{array}$ & $\begin{array}{c}-0.060^{* *} \\
(0.025)\end{array}$ & & & $\begin{array}{l}-0.068 \\
(0.043) \\
\end{array}$ & $\begin{array}{c}-0.147^{* *} \\
(0.064)\end{array}$ & & \\
\hline Controls & YES & YES & YES & YES & YES & YES & YES & YES \\
\hline Year fixed effect & YES & YES & YES & YES & YES & YES & YES & YES \\
\hline City fixed effect & YES & YES & YES & YES & YES & YES & YES & YES \\
\hline Observations & 2242 & 768 & 828 & 646 & 2242 & 768 & 828 & 646 \\
\hline $\mathrm{R}^{2}$ & 0.962 & 0.976 & 0.952 & 0.974 & 0.446 & 0.494 & 0.429 & 0.550 \\
\hline
\end{tabular}

Notes: Standard errors, which appear within parentheses, are heteroskedasticity robust and clustered at the city level. ${ }^{*}{ }^{* *}$, and ${ }^{* *}$ indicate statistical significance at the $10 \%, 5 \%$, and $1 \%$ levels, respectively.

As shown in column 1, annual coefficients indicate that the economic effects of HSR took several years to emerge in the cities considered. The coefficients become statistically significant from the 4th year onward, and the effects increase over time. In column 5, the coefficients of the first three years are significant, indicating that the HSR has a short-term effect on employment.

From columns 2 and 6, the economic and employment effects in the eastern cities show trends similar to those for the cities taken as a whole. The effects on economic growth appear with a time lag and those on employment are insignificant. The economic effects of HSR in the cities of the middle and western regions, shown in columns 3 and 4, are mainly positive, indicating that HSR has more of a promotional effect, than a negative effect. The employment effect in the middle cities, indicated in column 7, is similar to that for the cities taken as a whole, which shows short-term effects. However, the employment effect of HSR on the western region shows a negative effect. Figures 1 and 2 provide a more direct representation 
of the economic and employment effects of HSR, using dynamic graphs, and the cap lines represents $95 \%$ confidence intervals.

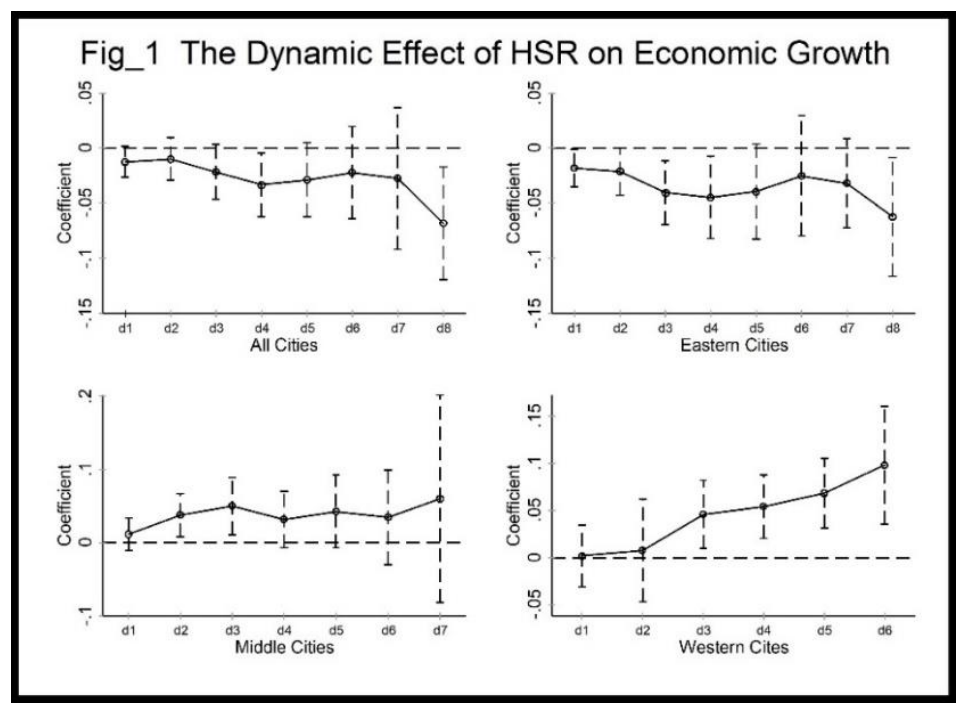

Figure 1. The dynamic effect of HSR on economic growth

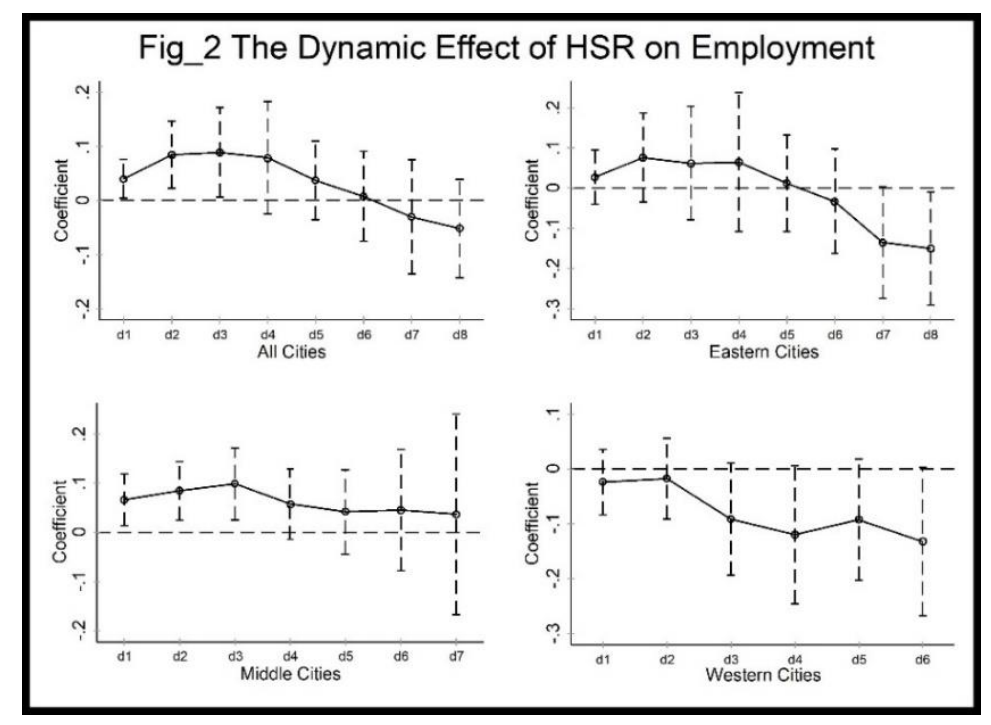

Figure 2. The dynamic effect of HSR on employment

\section{Mechanism of the HSR Effect on Economic Growth}

Interestingly, according to the series of regression and test results presented above, HSR has not promoted economic growth in all the cities and in eastern cities. What countervailing factors override the economic effect of HSR? To answer this question and identify the mechanism of the economic effect, we next examine HSR's impact on various economic growth factors.

Having found that HSR affects economic growth through the flow of investment and economic resources, market size, and other economic growth factors, we now explore three potential channels that explain the HSR impact: (1) HSR can affect the transportation infrastructure and associated infrastructure investments have a direct effect on the regional economy. (2) HSR is conducive for the rapid agglomeration of economic resources from the 
surrounding cities to the central city. (3) It also affects the city's market size, degree of openness and industrial structure. Therefore, we use total import and export as percentage of GDP, gross fixed investment as percentage of GDP, fiscal expenditure as percentage of GDP, and the tertiary industry share as the explanatory variables, to estimate a two-way fixed effects model. The results are shown in Table 3.

The results in Table 3 indicate that degree of openness and investment are the core factors that affect economic growth. As shown in Panels A and B of Table 3, the reduction in economic growth for all cities taken together and in the eastern cities is mainly accounted for by the decline in the degree of openness. From Panel C of Table 3, the increase in middle cities is explained by the increase in degree of openness and investment. In addition, Panel D indicates that HSR has only a weak influence on fiscal expenditure.

Table 3. The impact of HSR on regional economic growth: mechanism test

\begin{tabular}{|c|c|c|c|c|}
\hline Variables & Import \& Export & Investment & Fiscal Expenditure & $\begin{array}{l}\text { Industrial } \\
\text { Structure }\end{array}$ \\
\hline & \multicolumn{4}{|c|}{ Panel A: All Cities } \\
\hline \multirow[t]{2}{*}{ HSR_city } & $-0.023^{*}$ & -0.011 & $-0.008^{* * *}$ & 0.004 \\
\hline & $(0.014)$ & $(0.018)$ & $(0.003)$ & $(0.004)$ \\
\hline Observations & 2,250 & 2,250 & 2,250 & 2,250 \\
\hline \multirow[t]{2}{*}{$\mathrm{R}^{2}$} & 0.061 & 0.482 & 0.399 & 0.316 \\
\hline & \multicolumn{4}{|c|}{ Panel B: Eastern Cities } \\
\hline \multirow[t]{2}{*}{ HSR_city } & $-0.059^{* * *}$ & -0.001 & -0.001 & -0.002 \\
\hline & $(0.021)$ & $(0.023)$ & $(0.003)$ & $(0.005)$ \\
\hline Observations & 774 & 774 & 774 & 774 \\
\hline \multirow[t]{2}{*}{$\mathrm{R}^{2}$} & 0.154 & 0.395 & 0.664 & 0.510 \\
\hline & \multicolumn{4}{|c|}{ Panel C: Middle Cities } \\
\hline \multirow[t]{2}{*}{ HSR_city } & $0.026^{*}$ & $0.044^{*}$ & $-0.009^{* *}$ & -0.001 \\
\hline & $(0.015)$ & $(0.024)$ & $(0.004)$ & $(0.005)$ \\
\hline Observations & 828 & 828 & 828 & 828 \\
\hline \multirow[t]{2}{*}{$\mathrm{R}^{2}$} & 0.050 & 0.634 & 0.641 & 0.400 \\
\hline & \multicolumn{4}{|c|}{ Panel D: Western Cities } \\
\hline \multirow[t]{2}{*}{ HSR_city } & 0.001 & -0.036 & $-0.015^{*}$ & -0.005 \\
\hline & $(0.020)$ & $(0.055)$ & $(0.008)$ & $(0.011)$ \\
\hline Observations & 648 & 648 & 648 & 648 \\
\hline $\mathrm{R}^{2}$ & 0.013 & 0.483 & 0.286 & 0.277 \\
\hline Year fixed effect & YES & YES & YES & YES \\
\hline City fixed effect & YES & YES & YES & YES \\
\hline
\end{tabular}

Notes: Standard errors, which appear within parentheses, are heteroskedasticity robust and clustered at the city level. ${ }^{*},{ }^{* *}$, and ${ }^{* *}$ indicate statistical significance at the $10 \%, 5 \%$, and $1 \%$ levels, respectively.

\section{Conclusion and Policy Implications}

This paper model the impact of HSR on the cities along the line from the perspective of economic growth and employment based on the concepts of new economic geography and traffic economics. Using a sample of 284 Chinese cities that are at the prefecture-level or above, it evaluates, through empirical tests based on DID analysis, whether HSR has an impact on the regional economy and employment. The results are as follows: (1) HSR scales down the economic development of cities along the line and, from a national perspective, 
decreases GDP per capita by $1.5 \%$; however, it has a significant positive impact on the employment scale of cities along the line, with a regression coefficient of $4.8 \%$. (2) The economic and employment effects of HSR vary across regions. HSR construction has an inhibitory effect on economic growth, but has no significant effect on employment in the eastern cities. In the middle cities, the commencement of HSR operation significantly improves the economic growth and employment level in cities along the line. (3) Regarding the impact mechanism, the economic effects occur through the degree of trade openness and investment.

Based on the findings of this study and after considering the current status of China's high-speed rail construction, we offer the following policy recommendations:

(1) Establishment of suburban and inter-city railways should be speeded up along with the construction the HSR trunk road network (the "eight horizontal and eight vertical" lines). Due to the high cost of HSR construction, the gap between planning and construction is relatively large, and the economic spillover effects are not fully achieved in the establishment of hub cities and the rapid development of the surrounding areas and cities, especially the core cities and their satellites Therefore, while building HSR networks, we must place greater importance on the construction of suburban and inter-city railways.

(2) Various types of cities should seize the opportunity provided by HSR and promote their all-round social and economic development. The core cities should actively develop the hub economy, wherein all modern modes of transport are used in an integrated manner, to accelerate the outward transfer of low-end industries, vigorously develop the modern service industry, and transform and upgrade the three new economies which include new industries, new formats and new business models. They should take full advantage of the status of hub cities, actively attract high-end talent, and encourage capital accumulation, thereby providing a new impetus for rapid development. Small- and medium-sized cities along the line should seize the opportunity offered by HSR and show the initiative to undertake and extend the industrial chain of the core cities. They should do so as per their development positioning and advantages so as to integrate with the urbanized economy. Non-HSR lines should be connected to the HSR network to avoid large-scale loss of the labor force in regions without HSR.

(3) We propose that HSR construction should be taken up in an orderly manner in the western part of the country in the 13th Five-Year Plan for Western Development. In response to the new round of HSR construction plans, all cities should calmly assess the costs and benefits of HSR construction. Instead of blindly setting up stations for HSR, they should launch a series of "road-racing" rounds (Zhang, 2017).

Due to the limitation of data availability, although this paper has a lot of discussion on the economic and employment effects of HSR, it fails to discuss the impact of HSR on enterprises from a micro-level. Also, there are the following aspects that can be expanded: first, the construction of HSR has increased the degree of economic connection between regions, so we will further investigate the spatial spillover effect of HSR from the perspective of spatial measurement; second, we plan to examine the overall impact of HSR on resource allocation efficiency in each region in the future, i.e. the impact on total factor productivity. 


\section{References}

Beck, T., Levine R., \& Levkov, A. (2010). Big bad banks? the winners and losers from bank deregulation in the United States. Journal of Finance, 65(5), 1637-1667. https://doi.org/10.1111/j.1540-6261.2010.01589.x

Chandra, A., \& Thompson, E. (2000). Does public infrastructure affect economic activity? evidence from the rural interstate highway system. Regional Science \& Urban Economics, 30(04), 457-490

Deng, T. T., Wang, S. Y., \& Cheng, S. Y. (2017). The impact of high speed railway on urban service industry agglomeration. Journal of Finance and Economics, 43(07), 119-132

Donaldson, D., (2018). Railroads of the raj: Estimating the impact of transportation infrastructure. American Economic Review 108, 899-934

Dong, Y. M., \& Zhu, Y. M. (2016a). Can High-Speed Rail construction reshape the layout of China's economic space-Based on the perspective of regional heterogeneity of employment, wage and economic growth. China Industrial Economics, 10, 92-108

Dong, Y. M., \& Zhu, Y. M. (2016b). Study on the employment effect of the construction of High Speed RailwayEvidence from 285 cities of China based on PSM-DID method. Business Management Journal, 38(11), 26-44.

Duranton G., \& Turner M. A. (2012). Urban growth and transportation. The Review of Economic Studies. 79(4), $1407-1440$

Faber, B. (2014). Trade integration, market size and industrialization: Evidence from China's national trunk highway system. The Review of Economic Studies, 81(3), 1046-1070

Hall, P. (2009). Magic carpets and seamless webs: opportunities and constraints for high-speed trains in Europe. Built Environment, 35(1), 59-69

Hoyne H., Schanzenbach, D. W., \& Almond, D. (2016). Long-run impacts of childhood access to the safety net. The American Economic Review, 106(4), 903-34

Li, H., Shen, Y. M., Meng, D., \& Xue, J. (2013). The city network centrality and spatial structure in the BeijingTianjin-Hebei metropolitan region. Economic Geography, 33(08), 37-45

Li, H. C., Tjia, L., \& Hu, C. X. (2016a). Agglomeration and equalization effect of high speed railway on cities in China. The Journal of Quantitative \& Technical Economics, 11(33),127-143

Li, H. C., Tjia, L., \& Hu, C. X. (2016b). Causality relationship between high speed railway and economic growth. Journal of Chang'an University (Social Science Edition), 18(4), 31-43

Li, X. M., Liu, Y. Z., \& Cao, L. P. (2014). Research about the influence of population space of flow under the highspeed railway construction. China Population, Resources and Environment, 24(6), 140-147

Long, F. (2017). High-speed railway and venture capital investment. Economic Research Journal, 52(04), 192-208

Ortega, E., López, E., \& Monzón, A. (2012). Territorial cohesion impacts of high-speed rail at different planning levels. Journal of Transport Geography, 24(4), 130-141

Moser, P., \& Voena, A. (2012). Compulsory licensing: evidence from the trading with the enemy act. The American Economic Review, 102(1), 396-427

Shaw, S. L., Fang, Z., Lu, S., \& Tao, R. (2014). Impacts of high speed rail on railroad network accessibility in China. Journal of Transport Geography, 40, 112-122

Datta, S. (2012) The impact of improved highways on Indian firms. Journal of Development Economics, 99(01), 4657

Tan, C. L., \& Yang, Q. Q. (2016). Development of high-speed railway and producer services agglomeration. Economic Survey, 33(03), 1-6

Tan, C. L., \& Yang, Q. Q. (2017). The effect of HSR on the spatial pattern dynamics of producer service. Economic Geography, 37(02), 90-97

Wang, M., \& Nian, Y. (2013). Did High-Speed Trains Promote the Development of Regional Economy? Shanghai Journal of Economics, 2, 82-91

Wang, Y. F., \& Ni, P. F. (2016). Economic Growth Spillover and Spatial Optimization of High-speed Railway. China Industrial Economics, 02, 21-36

Zhang, J. (2017). High-speed rail construction and county economic development: the research of satellite light data. China Economic Quarterly, 16(4). 1533-1562

Zhang, X. L., \& Nie, H. K. (2010). High-speed rail construction and the regional economic integration in China. Modern Urban Research, 25(6), 7-10

Zhang, X. L. (2012). Has transport infrastructure promoted regional economic growth? - With an Analysis of the spatial spillover effects of transport infrastructure. Social Sciences in China, 34(2), 24-47 